\title{
DIGITIZATION OF THE STUDENT LIFE CYCLE TO PROMOTE UNDER-REPRESENTED GROUPS IN STEM SUBJECTS
}

\author{
Heidi Schuhbauer and Patricia Brockmann \\ Technische Hochschule Nürnberg Georg Simon Ohm \\ Postfach 120320, D-90121 Nürnberg, Germany
}

\begin{abstract}
A project to support underrepresented groups in STEM (Science, Technology, Engineering and Math) subjects is being carried out at the Department of Computer Science at the Technical University of Nuremberg Georg Simon Ohm (TH GSO). This project intends to counteract the shortage of specialists in the STEM occupations by supporting underrepresented student groups (i.e. students with a migration background, from non-academic households, female students, and single parents) before, during and after their studies. To this end, digitization measures in STEM studies should be evaluated and carried out at the TH GSO Nuremberg. The entire life cycle plays a decisive role in this, starting with the choice of the students' course of study, through their university or college studies, to entry into the labor market, and is included in this research project. Specific digital prototypes will be developed as supporting measures. The identification of underrepresented groups of students in STEM subjects is the starting point of this project. At the beginning of the student life cycle, the identified groups should be provided with information about STEM fields to support their choices of study subjects. For this purpose, some digital advisory tools will be developed. To prevent them from breaking-off their studies, influencing factors have to be identified. Knowing these factors, an early-warning system will be developed. This system should identify students who are at risk of failing and propose supporting measures to them at an early stage. At the end of their studies, they should be assisted in their choice of a suitable job and in applying for jobs with digital tools.
\end{abstract}

\section{KEYWORDS}

Computer Science, Digital Measures, Diversity, Shortage of Specialists, Education

\section{MOTIVATION}

In a society shaped by science and technology, the STEM labor market has attracted a lot of attention for years. Digital networking is increasing. Digitalization is changing how and where we work and the way we act in society. Rapidly increasing digitalization increases the importance of STEM (Science, Technology, Engineering and Math) education. Overall, there is a growing demand for STEM professions [Bundesagentur für Arbeit 2018]. Carnevale et al. state that "there is added pressure to find more STEM workers due to baby boomer retirements" [Carnevale et al. 2011, p. 53]. They note that more women and minorities in STEM jobs are necessary [Carnevale et al., p. 69].

Due to the continuing high demand for qualified personnel in STEM professions, one of the most important preconditions is a sufficient number of graduates in STEM subjects. More than ever before, we are challenged to qualify as many suitable candidates as possible for the job market in technical studies. Therefore, we must consider how we can acquire applicants for STEM studies from groups that are currently underrepresented among our students. These include students with a migration background or young people from non-academic households. Of course, we aim to increase the proportion of women in technical professions. According to Cohoon [Cohoon 2003], although the proportion of women in mathematics, biology and physics has increased, the proportion of women in computer science has remained low. Blum et al. [Blum et al. 2007] postulate that women often do not enter the field of computer science due to influences from their environment and culture as well as their perception of the field. They recommend appropriate public relations work, education and methods to improve micro culture in order to increase the participation 
of women in computer science. Ilmuoka [Ilmuoka 2012] discusses the importance of diversity in the workplace to generate a creative variety of thinking styles that promotes problem solving and innovation. She recommends a comprehensive STEM immersion program that starts at school to overcome obstacles for disadvantaged groups in the classroom. Convincing and supporting potential students from underprivileged groups increases the pool of qualified STEM graduates.

The aim of the project that is described in this article is to support students from underrepresented groups in all phases of their studies. This support should be target group oriented. To this aim, digitization opportunities should be uncovered and digital solutions should be implemented at the Technical University Georg Simon Ohm in Nuremberg, Germany. According to Gartner's IT Glossary, "Digitization is the process of changing from analog to digital form, also known as digital enablement" [Garnter] whereas digitalization means the use of digital technology to change business models. The aim of this research project is to investigate, introduce and evaluate digitization procedures in STEM studies with the intention of attracting and supporting new candidates for STEM studies from underrepresented groups before, during, and after their studies. Schuhbauer [Schuhbauer 2018] describes a framework for digitalization in education. This is used as a basis for developing digitized courses of action.

In the next chapter, this article describes related works, followed by the methodology of the project. After that, the article defines the different elements that are part of the research project. At the end, it shows how the evaluation should be done.

\section{RELATED WORKS}

Several related works discuss the topic of minority students in higher education. Swail [Swail 2003] states that pre-college preparation, admission policies, affirmative action, and financial aid are important factors, but campus-wide support, from the chancellor's office to the classroom, is critical to success. Rendón et al. [Rendón et al. 2000] deal with different models for minority student retention in higher education. They note that students elect to stay or leave college because "college and university faculty and administrators have made transformative shifts in governance, curriculum development, in- and out-of-class teaching and learning, student programming, and other institutional dimensions that effect students on a daily basis." [Rendón et al. 2000, p.152] They propose that retention research should include collaborative relationships and mutual learning experiences [Rendón et al. 2000, p. 152]. Birnbaum [Birnbaum 1983] declares that diversity in higher education is important for different types of students. Limiting the field to minority students in STEM subjects, there are also a number of studies. Anderson and Kim [Anderson \& Kim 2006] address different dimensions of ensuring the success of students of color in science and technology in the United States. They emphasize the need for academic and financial support. They identified the working hours of students as one negative predictor of obtaining a bachelor's degree. They write: "The key is for higher education institutions to know how to better identify those students who need support - and what type of support, both academic and financial, would be most helpful - in order to be successful in the STEM fields." [Anderson \& Kim 2006, p. 16] Museus and Liverman [Museus \& Liverman 2010] focus also on students of color in STEM subjects. They analyze successful institutions to shape future research on students of color in STEM.

The project that is described in this article focuses on digitized solutions. The influence of digitalization in education is discussed in Schuhbauer [Schuhbauer 2018]. She recommends actions that should make education fit for the digital future. These are the recommendations:

- Both teachers and learners must become aware of the extent to which the changes through digitization and networking will influence education. Dynamic and velocity of changes in technology necessitates life-long learning. Education is no longer just a matter of conveying content. Dealing with change must become the subject of qualification procedures.

- Dealing with technology must not be an obstacle. Therefore, teachers and learners should be qualified to handle technology. Using technological equipment has to be taught theoretically and exercised practically. Educational institutions need a modern digital infrastructure. 
- Learners should be enabled to learn self-reliantly using electronic media. To provide electronic educational material, teachers should be enabled to utilize online courses, blended learning, gamification, and learn management systems.

- Methods of learning have to be part of the teaching material. The teacher increasingly assumes the role of a guide and shows how and from where learners can acquire knowledge and how they can acquire it. Teaching staff must be qualified to do this.

- These recommendations mean that digitalization and networking require the revision and adaptation of educational guidelines. Educational guidelines for digitalization have to be developed and implemented. Therefore, knowledge about prospective job profiles is necessary.

Dahlström and Doracic [Dahlström \& Doracic 2009] describe the aim and challenges of digitization education. They point out the challenges of digitization in education and their way to tackle them. Perry [Perry 2005] examines the characteristics and variety of digitization training initiatives. She "briefly discusses the benefits and challenges associated with the development of digitized library resources, and the need for greater attention to professional development for those working in digitization" [Perry 2005, p. 523].

The research goal for this project is the use of digitization to support underrepresented groups in STEM subjects. This project combines the focus on underrepresented groups with the megatrend digitalization. The research questions are: Which groups of potential students need special support? Which activities of the student life cycle do not match the expectations of these focus groups? Which digital tools can improve the uncovered situations?

\section{METHODOLOGY}

An adequate phase model of the student life cycle for our research project shall be determined methodically, e.g. by document analyses, with machine learning, observations and surveys. Therefore, existing phase models have to be identified and analyzed. Based on the requirements analysis, a life cycle model suitable for the research purpose is to be designed.

The life cycle of a student begins even before the official enrolment at a university. Before a candidate makes a decision for a STEM degree of study, he tries to find out which university is most suitable for him. A student's life cycle can end when the student has completed his studies. However, there are models in which the cycle continues through the alumni phase or entry into working life.

In the first step, an elemental model for the project was defined which has to be further developed over the course of the project. The aim of the project is to support students of the target group before, during, and after their studies. Therefore, the concept of a student life cycle is an adequate framework for the project. A simplified version that is the basis for our project definition phase is shown in Figure 1.

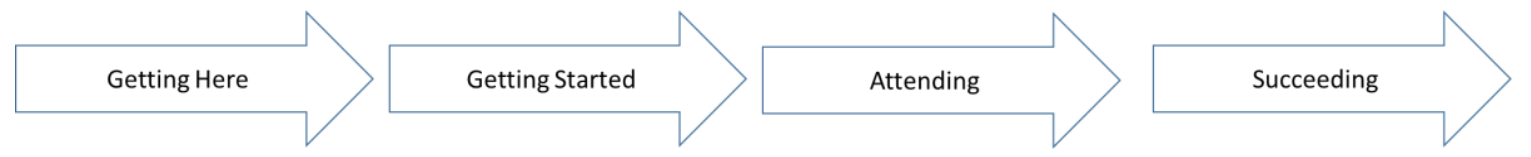

Figure 1. A simplified version of the students' life cycle [Pipitone \& Poirer]

"Getting Here" includes services that help students to select a course of studies and to get settled. "Getting Started" includes services that support students' orientation at the university and in their selected courses. "Attending" includes all of the services, which support academic delivery. "Succeeding" includes services which support students to complete their studies and to enter into a career. For this project, the state "Getting Here" is contained in Phase 1 "Before Studies". The two states "Getting Started" and "Attending" are handled in Phase 2 "During Studies". The state "Succeeding" is in project Phase 3 "After Studies". The life cycle of the students (Figure 2), starting with the choice of the course of study of the students, through their studies at the university or college up to their entry into the labor market, plays a decisive role and is included in this research project. 


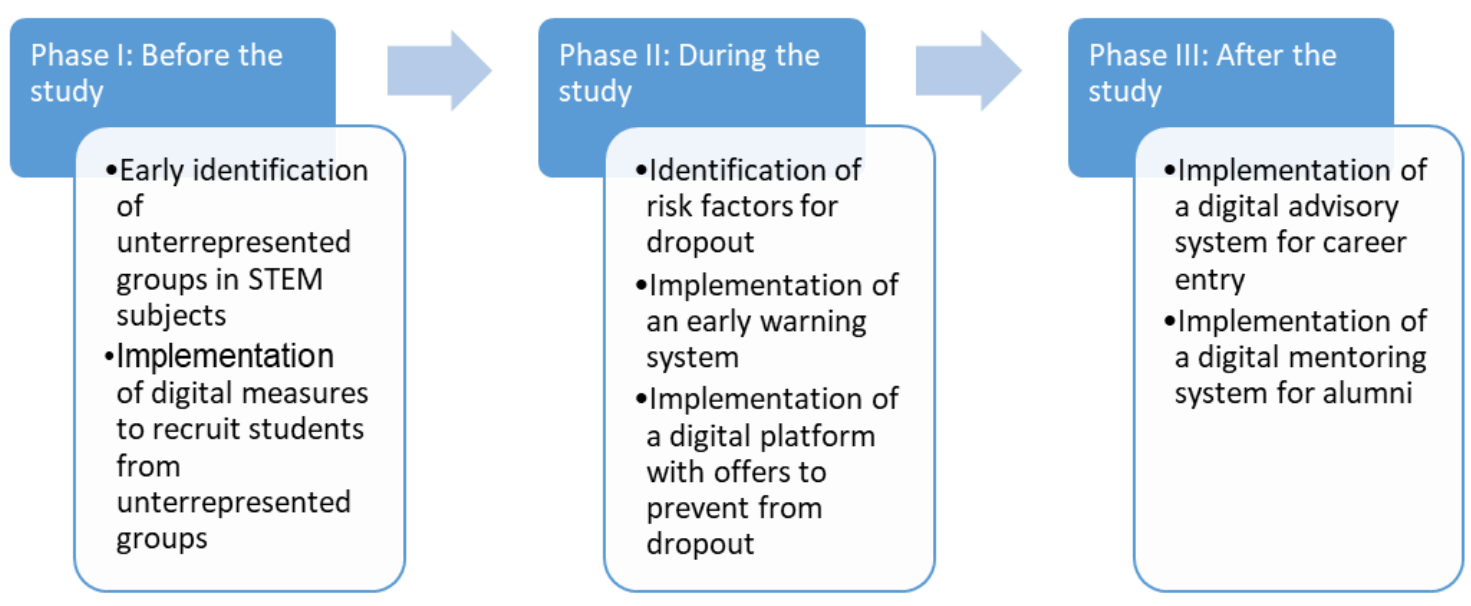

Figure 2. Aim of the project according to the students' life cycle

Subsequently, concepts will be developed for the underrepresented groups of students identified for the respective life cycle phases, which show support possibilities through digitization. The target groups will test the results of the first prototypes developed in the following year at the Technical University of Nuremberg. The results of these initial tests will be used in the further development of prototypes and in the technical implementation of new procedures.

Aim of the research project described is to investigate possibilities to assist persons from underprivileged groups at every phase of the students' life cycle during their studies and to implement some of the ideas as digital tools. The next section describes ideas for this purpose.

\section{PHASES OF THE STUDENT LIFE CYCLE}

The project consists of several small projects. They refer to the student life cycle and are introduced in this section.

\subsection{Before their Studies}

At the beginning, it is important to identify the target group. Their decision making process for a STEM study should be influenced positively.The group of disadvantaged students should be identified at an early stage. For this purpose, statistical data from the students' database at the Technical University Georg Simon $\mathrm{Ohm}$ can be evaluated. It has already been established for all courses of study at the Technical University of Nuremberg that $65 \%$ of students come from non-academic families, about $5 \%$ of students have children, $10 \%$ are international students and 5\% are so-called occupationally qualified persons without classical university entrance qualifications [Technische Hochschule Nürnberg]. Further data analysis, especially for STEM, are part of this project. Based on a first view on the database of the Technical University of Nuremberg and external studies, it is hypothesized that that following groups are underrepresented in STEM studies:

- students with children,

- students with family members in need of care,

- disabled students,

- students with a migration background,

- students from non-academic households,

- students with financial needs, 
- students with special social or personal circumstances (e.g. depressed), and

- students with special academic needs (lack of prior knowledge for the course of studies).

These hypotheses have to be tested. Results of related research projects, for example from the social sciences, and studies (e.g. from [Deutsches Zentrum für Hochschul- und Wissenschaftsforschung]) should be integrated. The aim is to clarify which groups are underrepresented in the STEM degree programs.

In the phase where pupils gather information about study possibilities, the specific target groups should be informed about STEM studies. Studies, questionnaires and interviews with the target groups will be carried out, which will form a database for the analysis and evaluation of attitudes, expectations and factors which influence the decision-making process in the selection of the future study program. These results should reveal relevant decision factors.

Potential students should receive structured and comprehensive information about courses of study. Guidance on the choice of studies should be offered to them in order to positively influence the decision factors for selecting a STEM subject. Digital tools should be developed for that purpose. The first step will initially be a prototype for an information and advisory portal. This portal should guide the choice of study subjects by providing information that is especially important for minorities. This portal solution should be tested and evaluated at some schools in Nuremberg.

\subsection{During their Studies}

Advisory tools and social media can advise students during the enrollment phase.

During the lecture phases, underrepresented groups may require special help or advice. Some students need subject-specific support (e.g. because of language problems or lack of previous knowledge) or flexible learning times (e.g. because of childcare). Learning concepts from literature have to be identified and evaluated in order to assess their suitability for these groups. From this, concepts have to be developed, which support them and enable them to learn in a self-directed way.

A research question is how attendance at lectures, preparation and follow-up of courses, the processing of exercises, etc. can be supported through digital technologies. Initially, the influence of digital measures on students' success has to be analyzed. Based on the evaluation of questionnaires, interviews, experiments, and analyses of social media, students' opinions on the current digital educational measures of the Technical University of Nuremberg are collected and subsequently analyzed with regard to their acceptance and effectiveness. Successful methods should be strengthened.

The examination phases can put students from underrepresented groups under particular pressure. Therefore, the preparation for and taking of examinations should be supported by advisory systems. A portal could help students with questions to find helpful contacts. These students also often require special help in writing papers, e.g. reports, seminar papers and dissertations. Students from non-academic backgrounds and students with a migration background in particular experience difficulties here and are often left alone. For them, offers of help which feature a low inhibition threshold are to be developed.

Dropping out of the university should be prevented. Reasons for dropping out which are specific to underrepresented students should be analyzed more precisely using questionnaires, interviews and study analysis. These results point out where special assistance is needed for these target groups. To prevent dropouts, an early warning and assistance system should be implemented as a web-based portal or mobile app, which informs students about digital educational measures, such as counselling and assistance services. A prototype for an early warning system using machine learning will be developed to identify students who are at risk. The students identified will test a prototype of the digital advisory system based on chatbot technology to obtain information about what types of support are available. Student advisors have reported that students from underrepresented groups often do not have the confidence to ask a professor for help. For these students, chatbots may provide a low-threshold source of information to help them. 


\subsection{After their Studies}

To support the target groups after their studies and help them to enter professional life, a database of career qualifications linked to job profiles should be developed. To prepare this database, job advertisements, labor market reports and labor market forecasts have to be analyzed. A forecast about the necessary skills for STEM graduates for the future is one project aim in this phase.

Since students from underrepresented groups often have few role models in STEM occupations, they are particularly grateful for advice when choosing a career profile. This advice can be provided using social media and digital advisory tools.

Solutions, e.g. in the form of portals, need to be developed for a successful entry into professional life and to provide support in the first work phase, with questions on employment contracts, labor law and also on further training opportunities.

An interesting aspect is the establishment of an alumni network. Particularly successful reports from graduates can be helpful in taking the fear out of studying for new students. Mentoring programs with digital information and communication tools should be implemented.

The process of lifelong learning can be supported with digital advice and e-learning offers.

\subsection{Accompany all Phases}

Though all of the phases of the student life cycle, the contact points between students and the university should be identified and described. To ensure that the results of this project are tailored to the specific target groups of the students, the points of contact between students and the university must be identified from the students' point of view and described using the modern method of digitization research called the "Customer Journey" [Neonen et al. 2008]. Touch points are defined as points of interaction (e.g. matriculation) and points of contact (e.g. gathering information on studies). All actions that students can take in connection with the university are described with Customer Journeys. The actions are presented in a process-oriented way. The difference to common process descriptions, however, is the perspective: the processes are not described from the point of view of the company or the university, but from the point of view of the customers or the students. These process descriptions form the basis for the discovery of digitization opportunities. Weak points in the processes should be documented and possible suggestions for improvement worked out.

Customer Journey Maps visualize customer processes (Customer Journeys) of an organization. In the context of this work, the university has to be seen as the company and the students as customers. Prospective students and applicants are also regarded as customers, as they are also part of the Customer Journey Analysis. In our project, the processes of students at a university have to be visualized. In order to create a Customer Journey Map, the touchpoints of student processes have to be recorded and evaluated as part of an analysis process (called Customer Journey Mapping). Such touchpoints usually generate internal processes that have to be operated by the organization. If there are changes at the touchpoints, the internal processes must be adapted accordingly. If only the touchpoints of a customer process are optimized and the internal process associated with these contact points is neglected, both process dimensions are desynchronized. Therefore, it is useful to consider the internal process view when analyzing customer journeys. In this way, both process dimensions can be analyzed and optimized simultaneously, taking into account possible interdependencies. The synchronization of the two dimensions takes place on the basis of the recorded touchpoints and internal interfaces as connection points between the process dimensions. [Schötteler 2018, p 19]. Figure 3 shows a template for a process analysis based on Customer Journey Maps. 


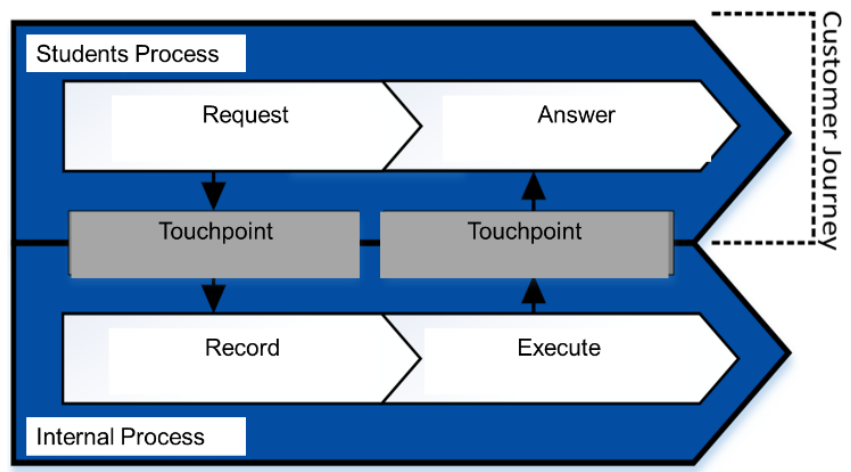

Figure 3. Template for Process Analysis Based on Customer Journey Maps

The touchpoint of students with the university which were identified and the corresponding internal processes reveal the possibilities where students can be contacted und supported by student advisors.

\section{COURSE OF PROJECT}

The project started in March 2019. A duration of eighteen months is planned. First, the data analysis has to be done. Afterwards, the work tasks of the three phases of the student life cycle start. Based on these results, some tools will be developed and evaluated by students. One prototype is a portal which should guide the choice of study subjects by providing information that is especially important for minorities. Another prototype is an early warning and assistance system to prevent dropping out of the university. It informs students about digital educational measures, such as counselling and assistance services. This tool should identify students who are at risk. The students identified will test a prototype of the digital advisory system and gain information about available help measures. A prototype for the phase "After their Studies" should assist minority students to entry into professional life. It should provide support in the first work phase, with questions on employment contracts, labor law and also on further training opportunities. This prototype has to be tested and evaluated by graduated minority students at the Technische Hochschule Nuremberg. The evaluation results of these prototypes are a valuable basis for further developments and for improvements of the developed solutions.

This project aims to especially support students from underrepresented groups in STEM subjects to increase the number of STEM graduates. Concepts will be developed for the underrepresented groups of students identified for the respective life cycle phases, which show support possibilities through digitization. The target groups will test the results of the initially developed prototypes in the following year at the Technical University of Nuremberg. The results of these initial tests will be used in the further development of prototypes and in the technical implementation of new measures.

\section{ACKNOWLEDGEMENT}

This work was supported by a grant from the STAEDLER foundation, as part of the project DIAMINT - Digitization of the student life cycle to support underrepresented students in STEM studies. 


\section{REFERENCES}

Anderson, E., and Kim, D., 2006. Increasing the success of minority students in science and technology.

Birnbaum, R., 1983. Maintaining diversity in higher education. Jossey-Bass, Inc., 433 California St., San Francisco, CA 94104.

Blum, L., Frieze, C., Hazzan O., and Dias, M.B., 2007, A Cultural Perspective on Gender Diversity in Computing. In: Reconfiguring the Firewall, P. Meszaros, A.K. Peters Eds., CRC Press, p. 109-133.

Bundesagentur für Arbeit, Blickpunkt Arbeitsmarkt, MINT-Berufe, September 2018, https://statistik.arbeitsagentur.de/Statischer-Content/Arbeitsmarktberichte/Berufe/generischePublikationen/Broschuere-MINT.pdf.

Carnevale, A.P., Smith, N., \& Melton, M. 2011. STEM: Science Technology Engineering Mathematics. Georgetown University Center on Education and the Workforce.

Cohoon, J.M., 2003, Must there be so few? Including women in CS. In: 25th International Conference on Software Engineering. Proceedings, p. 668-674.

Dahlström, M., and Doracic, A., 2009. Digitization Education. D-Lib Magazine, 15(3/4), 1082-9873.

Deutsches Zentrum für Hochschul- und Wissenschaftsforschung, https:/www.dzhw.eu/forschung/.

Gartner, Gartner IT Glossary Digitization, https:/www.gartner.com/it-glossary/digitization/.

Ilumoka, A., 2012, Strategies for overcoming barriers to women and minorities in STEM. IEEE 2nd Integrated STEM Education Conference, Ewing, NJ, pp. 1-4.

Museus, S. D., and Liverman, D., 2010. High-performing institutions and their implications for studying underrepresented minority students in STEM. New Directions for Institutional Research, 2010(148), 17-27.

Nenonen, S., Rasila, H., Junnonen, J.M., and Kärnä, S., 2008, Customer Journey-a method to investigate user experience. In Proceedings of the Euro FM Conference Manchester, pp. 54-63.Perry, C. A., 2005. Education for digitization: how do we prepare?. The Journal of Academic Librarianship, 31(6), 523-532.

Pipitone B., and Poirer, W., Student Services Revitalization/Transformation, http://collegequarterly.ca/2011-vol14num01-winter/pipitone-poirer-student-life-cycle.html.

Rendón, L.I., Jalomo, R.E., and Nora, A., 2000. Theoretical considerations in the study of minority student retention in higher education. Reworking the student departure puzzle, 1, 127-156.

Schötteler, S., 2018. Entwicklung eines Konzepts zur digitalen Transformation bei der IHK Nürnberg für Mittelfranken. Master Thesis. Technische Hochschule Nürnberg.

Schuhbauer,H., 2018, Proposal for a Framework for Digitalization in Education, ICERI2018 Proceedings, International Conference of Education, Research and Innovation, ISBN: 978-84-09-05948-5, pp. 2720-2726.

Swail, W.S., 2003. Retaining Minority Students in Higher Education: A Framework for Success. ASHE-ERIC Higher Education Report. Jossey-Bass Higher and Adult Education Series. Jossey-Bass, 989 Market Street, San Francisco, CA 94103-1741.

Technische Hochschule Nürnberg, Diversity an der Hochschule, https://www.th-nuernberg.de/hochschuleregion/strategie-und-profil/hochschule-der-vielfalt/. 